\title{
A CASE STUDY: ARE DIGITAL NATIVES DEAD? WHAT ARE THE KEY FACTORS AND PERCEPTIONS LIBRARIAN'S VIEW OF THE DIGITAL NATIVE CULTURE IN HIGHER EDUCATION?
}

\author{
Anthony F. Rodi, California University of Pennsylvania, rodi@calu.edu \\ Scott C. Spangler, Robert Morris University, scsst295@mail.rmu.edu \\ Frederick G. Kohun, Robert Morris University, kohun@rmu.edu \\ Gary J DeLorenzo, California University of Pennsylvania,delorenzo@calu.edu
}

\begin{abstract}
Digital natives have incorporated technology into all parts of their lives from smartphones to tablets, to smart appliances. The use of search engines has become a common tool for quickly finding answers for everything from restaurants to research. The ability to have knowledge and information instantly has created a culture of information rich and research poor students. Case study research was conducted at a mid-sized (9,000 students) public university in southwestern Pennsylvania where ten library staff members and one Dean were interviewed to create a case study about their reflections and considerations of the digital native culture. The results of the study listed five common factors: (1) digital natives don't like digital books; (2) digital journals are preferred over analog copies; (3) analog information is unacceptable; (4) instant gratification is key to elevating frustrations and anxiety; (5) digital natives lack the ability to use productive software and simplistic search tools.

While the research's findings provides correlation with the culture's need for instant gratification through digital mediums, it contrasts the abilities for digital natives to incorporate computer sophisticated software and innovations. Future research in this area could support the need for additional studies on the perceptions' of library science employees about the needs of higher education students and how to further incorporate technologies based on common student usage.
\end{abstract}

Keywords: Digital native, Digital archiving, Student research, Preservation, Digital preservation, University library digital archives, Preserving knowledge, Search engine.

\section{INTRODUCTION}

Digital natives are dead! You know, kids who don't know how to tell time without asking Siri? Well, in myth, they are dead at least! Or, maybe, they have been eaten by a digital platypus. Digital Platypus?

Nicholas Carr constructed a cyber-second life shallow grave for digital natives in his ground breaking book the Shallows in 2011 [6]? The digital natives lack intelligence because of the inability to carry a cognitive load. This is directly associated with how the Net is by design "an interruption system," that is forcing youth to have divided attentions and limited focusing abilities. Our influx for speed and instant gratification is creating the universal distraction or "cognitive interference" in the digital native culture and world today [6]. You can Google this, and Google that, but nothing that evolves around technology will ever remain the same for long. Gordon Moore's law (Moore's Law) contends "computer power" would double every eighteen months and everything "cycles" to solve new problems and situations [5]. Prensky's [15] digital native culture is considered to be cyber sophisticated and technologically advanced beyond mere digital immigrant's pea brain constraints. The term digital native has carried on now for over a decade.

This paper will suggest the term digital natives and the culture is nothing more than a myth today (2014). Maybe? This paper will interview ten university library staff members at a mid-sized (9,000 students) public university in southwestern Pennsylvania to create a case study about their reflections and considerations of the digital native culture. As indicated over the past decade, the use of technology continues to determine how students communicate, learn, and interact [17]. The paper will utilize Firat's [11] Multitasking or Continuous Partial Attention model to 
frame the case study. The case study will seek to understand the social impacts of new technologies, "with a goal of responsibility integrating technology into the academic culture" [20]. Zeitylyn and Houtman's [21] prior attention to computer cyberculture neglect reflection will frame the need for further studies to understand deeper connotations and implications of software knowledge in the culture. The paper will seek establish recurrent concepts or misconceptions the library staff members identify commonly through their daily communications with the digital native culture.

\section{"Digital Natives" Literature Review and of Terms}

The more technology is incorporated into life and everyday activities the less it is discernibly noticed as part of our activities. Consequentially, Information technology is concerned with "dissemination, processing, and storage of information" in everyday life through computerization [21]. Teachers are encouraged to integrate learning and technology into classrooms and academic experiences. Academic architectures are evolving to modularity rather than interdependency agents through technology. Disruptive innovations (are merely adaptations of "sustaining innovations" and not educational "breakthroughs improvements" [7]. Disruptive innovations are "valuable improvements" in technology but are less "relevant" to student-centered computer-based learning methodologies [7].

Digital natives are ascribed to be affluent with technology and computers. Current traditional students in higher education have grown up with and are engaged with numerous technologies related to many aspects of their lives. They are constantly plugged into social media, smart phones, Twitter, Youtube, Learning Management Systems, texting, and many other technologies [8]. They have "grown up with technology" and spent their "entire lives surrounded by and using computers, videogames, digital music players, video cams, cell phones, and all other toys and tools of the digital age" [15]. They are considered "native speakers" in the technology age that shun analog material and learn faster than others. They favor speed and the ability to multi-task through technology and have "little patience for lectures, step-by-step logic, and tell-tests instructions" [15]. Everything digital is delightful to the youth. E-books and connectivity are "liberating" to the youth and the culture [6].

Digital natives are suggested to have a "life-long experience" and relationship with technology because they were born into the innovations and media's [12]. Digital innovation age has "transformed" and changed minds and social activities in the digital native culture. The digital tool set, which has been absorbed the culture is different from any other generation's innovations [2]. The web and technology allows the youth to broadcast their lives 24/7 and, have global "access to anything, anywhere in the world." Digital natives use technology-based tools as a form of communication. Digital natives are always "connected to people" virtually through the social media tools [9]. Millennials "customized" their lives, environments, and life styles through the digital innovations [18]. Time zones and nationality once separated youth and friendships, today (2014) social media and sharing technologies has unified youth similar to past generations' "Pen Pals" snail mail methodologies [18].

The youth utilize the media to create a unified and "codified" cyber society [18]. The cyber environment establishes social norms, codes, and "open, consensual, and effective family units" digitally [18]. Natives uses of the innovations are "efficient and compelling," and require "a leap of imagination to recall what life was like before their advent" to cultural outsiders [2].

The youth have adapted a "collaborative" network of sharing and communicating through the virtual tools [3]. The culture seems "hardwired to collaborate," [3]. The "every man for himself" mentality of prior generations has decreased. Bell [3] expressed "opinions" are sought out by the youth through the digital tools [3]. Similarly, Evans [10] regarded the youth as innovated and collaborative.

The digital native culture loves distractions and all of their senses engaged at once in a "kaleidoscope" of visual and audio cues that creates a cognitive sensory obsession and overload. The culture has been ascribed to have a different 
social life and mental life or attitute towards technology and analog material. The digital technology and innovations are a source of "empowerment" and "awareness" in their "virutal communities" [1]. With the onset of J.K. Rowling's books, Harry Potter did activate a unified spark in the youth to read voluntarliy and use the technology to share thoughts [1]. Although, the technology itself is a tether or digital embilical cord to their parents and social wellbeing. The youth's need for constant connect is more of an after thought than a relationship to the medias. The technology ultimately acts as a disengagement device more than a thought social actuator [19]. The youth feel a need to continuously stream and broadcast life's developments and social interactions, one that may appear trivial to most, but in merit or value the actions are nevertheless a never-ending updating loop of self-conscious narcissism [19].

Although digital natives have self-esteem issues, they have no fear with new technologies and, or, innovations. When confronted with new technologies, and having not the slightest understanding or comprehension about how to utilize the mechanics of the device, digital natives will bypass "opening instruction" and simply try out the "gizmos" using their intuition. The youth are "wired" for digital devices and games by the time they reach college. They have a "sufficient motivation" and "innate expectation that they can learn by doing" [3]. This innate intuition proverb of their sophistication with technologies and gaming devices steers teachers and professors into a naïve assumption, or taking for granted perception of the digital native culture. This situation causes professors to take for granted the youth's abilities and presume that they don't need "instruction and guidance to maximize their productivity with these digital devices, communities, tools, etc. [3].

\section{Methodology}

The IRB at a mid-sized (9,000 students) public university in southwestern Pennsylvania approved the case study research. Ten voluntary participant Library staff members and one Dean were interviewed during week of February 10, 2014. Six males and four females were interviewed during the week long process. Each of the participants underwent a short scripted interview, which lasted no longer than 20 minutes. One of the interviews lasted over two hours, while most were contained to the allotted time. None of the volunteer participants refused any of the questions, and all of the participants interviewed offered extended data and additional thoughts on the digital native culture today (2014).

\section{Understanding the Volunteer Participant's Knowledge}

Only two of the participants said they have little to no experience in archiving digital data or knowledge and directly working with digital natives. Although all of the participants said they have each spent time helping students learning about digital knowledge, archiving, research report searching, and recovery processes.

All of participants stated they currently use computers to do their research. The participants remark commonly that they often rely "heavily" on computers to receive news and current events. Only two participants stated they preferred using E-books or digital books for research and reading, while the majority of the responders stated in common they have tried the digital books, but still prefer analog hard copies.

\section{Participant's Reflections on Digital Natives}

A major common thread in the participants disclosed an interesting fact about digital native students. Participants noted students prefer hard copy books before the digital versions. All of the participants agreed that students are having issues with the digital books. The common concern was that it was expensive to print out digital books and digital chapters. This thought contrasts Firat's [11] Multitasking or Continuous Partial Attention model that contends digital natives are progressive and prefer only digital media's. Additionally, and contrasting digital books, participants agreed that students do not want digital journals, or scholarly works in hard copies. A key common factor showed the participants believe "portability" and ease of use was the identifying factor in why students 
preferred digital journals. They also agreed that students would print out any and all digital copies of journals or book chapters. The students refuse to create digital notes on the PDF's of book passages.

A second common thread showed that students would rather change a research topic than search out a hard copy journal. All of the participants in common remarked students almost all refuse to search out hard copies of journals located in the library if the digital versions are not available. Interestingly, a common thread showed as one participant stated, students "will not even walk up one flight of stairs to get a hard copy journal if the digital version is not available." In agreement with Firat's [11] model, digital natives are technology originated, and the expressed disconnect from analog material exemplifies the culture.

A third common thread between the participants also saw students "changing research topics" when digital journals were not available. This thought reflects the idea that digital natives have a "radical" disassociation with pen and paper and prefer digital based media [11]. Student proficiency in search skills often involves employing the use of a search engine to gain a quick informative overview of a topic. When forced to conduct scholarly research with academic search tools involving library tools and databases, students experience difficulty because their learned search habits do not produce an effective search result [17]. In their study on perception and the actual use of information sources among undergraduate students, Kim and Sin [13] recognized behaviors of source selection such as perception of sources, familiarity, ease of use, efficient, accessible and accurate [13].

The digital native culture of immediacy and wanting everything "now" and at their fingertips is reflected in this speed orientated switching of topics. The key words participants cited to describe the digital natives were "instant," "portable," "quick," and "searchable." The use of search engines and portals among undergraduate students, provide a perceived free, quick, efficient use of resources that are easy to use, thus providing a one stop repository of resources. The use of higher quality sources such as journals and scholarly publications are less desirable and are perceived as less accessible and more difficult to navigate [13]. This data contrasts Firat's [11] model that contends digital natives fluent in all medias electronic and have an easy in circumnavigating the digital domains. In the age of multiple forms of electronic engagement and communication, where everyone has the opportunity to "be an author, a commentator, and a contributor," lies a resistance of digital natives to traditional research and information gathering. Their information expectations are where the next digital interaction takes them [4].

The commonality keys between the participants regarded digital natives library needs and usage as task focused, and unable to maintain concern if there was not direct satisfaction. The students followed the findings of Firat [11] of "redefining attention and focus," when instant digital material was not readily accessible [11]. Hard copy materials were considered "Taboo" by one participant according to one participant's views of students searching requirements in the library. Undergraduate users of information seek the immediate return on their efforts in place of a greater return based on more effort at higher levels of research. The minimal efforts exerted by students in their research endeavors are indicative of lack of motivation and experience in regards to the use of information. It may also be reflective of the Digital Native culture and attitudes towards technology versus information [13].

All of the participants reflected negative regards towards attempting to use digital notes in books and journals. Each of the participants also considered this a key factor why students still want to print out journals and books. The participants had a unified regard stating students are using their high-tech scanning stations to digitalize hard-back books and journals. They found a key factor that students would scan analog material into a digital medium, to then only print the material back out for personal copies to take analog notes in the margins.

\section{The Digital Native Myth}

The common thread from participants showed that there is a common "myth" or misconception in 2014 digital native culture. Digital native students are not fluent in technology platforms. All of the participants found student frustrations in their lack of knowledge in research software available in the library. The digital natives' library 
research platform knowledge is limited. A key factor arouse when each of the volunteers cited cases and stories about finding digital natives in fits of frustration and anxiety over not being able to find resources through the library's basic software searching platforms. The main cause of frustration or key factor thread was that digital native students don't understand how to "key word" search. Google has become the dominant search tool for students conducting scholarly research, with decreased use of Library Services reference tools and databases. Many students do not know that scholarly research takes place outside of a search engine [16].

All the participants cited seeing students having difficulties in understanding digital researching "tools." The participants' were united in thoughts finding and seeing students having frustrations with getting materials because they use the searching platforms like "Google."

Information searches have resulted in typing in a keyword or phrase into a search engine and expecting instant gratification from Google or another search engine. The process of searching for information does not initially start with library resources. Even after purchasing expensive electronic journals, the preferred method of information searches is still the search engine due to its familiarity, ease of use and less frustrating search efforts. The biggest challenge to efficient information searches is the preference to the one search that leads to all resources [14]. Again, this data contrasts Firat's [11] Multitasking or Continuous Partial Attention model that contends digital natives are digitally fluent.

Interestingly, all of the participants remarked that they have witnessed the digital natives utilizing the libraries scanning technology to convert their analog material to digital device worthy data. Although, they also cited witnessing frustrations and anxieties over the medias not being compatible with their smart phones and, or, tables. This visual frustration assessment led participants to consider the digital natives as playing "catch up" to basic course and productivity software utilities or tools. One participant cited the fact that the digital native international students lack additional skills possible due to a digital gap consideration that the college has not addressed. One student, described as an Arabic speaking and international student couldn't articulate his needs, and felt embarrassed to ask for additional help from the library staff because of his deficiencies in knowledge.

This knowledge was not just limited to international students. Many of the participants cited conditions were digital natives lacked the simple ability to utilize QR codes they had created around the library on posters to link into additional information. Students overwhelmingly had no understanding of the QR Codes, and how to "download" smart-phone software to link into the data the codes stored. This misunderstanding followed Bell [3] considerations that the natives lacked abilities in understanding QR codes and simplistic presumed technology matrixes. This idea or concept creates a paradox in the actual knowledge of digital natives and the presumed knowledge understood by professors, librarians, and teachers on college campuses. This is reflected in one male participants views of the digital natives stating, "Everything is about speed. They have little knowledge, and can't even log in most of the time. They never know their user name, and seem behind the distance (past) students. They have little knowledge about computers. And once they seem to understand this, I see them feeling ashamed and overwhelmed."

Another congruent thought among the participants was the fact that they discovered digital natives became very frustrated when their media, more importantly "portable medias," such as iPads and tablets would not integrate digital sources from the library. This methodology conflict was seen as a reason for the digital natives to neglect, and overstep utilizing E-Books and other forms of digital media that were to be "integrated" and ready for easy and use. Portability was one reason the students' neglected utilizing traditional analog or hardcopy materials according to the library staff and dean. Non-integratable knowledge or information was seen as meritless to their research and searches. One participant male remarked, "Easy is the main concern for the digital natives. Ninety percent of them will find a digital media and then print it out, and store it (information) digitally to reduce their cognitive load." Another participant noted, "Their mission is to get it (information) quickly. They would even consider history or special collection, since their narcissistic behavior wants everything just in time." Another staff librarian remarked, 
"They have to have it digital, but digital methods like microfiche films are taboo. They are so fragmented in abilities and their topics. They don't understand how to do digital searches, and they don't know what they want or how to get what they want through the media." These thoughts expressed highlight Firat's [11] model, and indiscriminately point out "continuous partial attention" description in the culture, which appears to be fluctuating in nature.

Other participants remarked the digital natives are very unhappy about their abilities to search and find information. The majority of digital natives "don't ask for knowledge [searching] help." One female participant stated, "They are so frustrated with user friendly data bases. They need training and tool training. They become so frustrated when they can't find information that they become disconnected. They have a purported ability [level], but it's different from their actual abilities. If it's not quick, a quick transition or searchable, and digital (no E-books, as nobody wants paper), then they go to websites. They only want what's available."

\section{CONCLUSIONS}

Five common factors came from the study: 1) digital natives don't like digital books; 2) digital journals are preferred over analog copies; 3) analog information is unacceptable; 4) instant gratification is key to elevating frustrations and anxiety; 5) digital natives lack the ability to use productive software and simplistic search tools. This research's findings correlate with recent scholar's reflections on the culture's need for speed and digital mediums, but contrasts their findings about the digital natives abilities with computer sophisticated software and innovations.

Table 1: Common Factors of Digital Natives Study

1. Digital Natives reject digital books

2. Digital Journals preferred

3. Analog information unacceptable

4. Instant gratification elevates frustration

5. Digital Natives lack ability to use productive software and simple searches

This paper suggests a gap in the literature about digital natives. It proposes another case study be conducted that would engage deeper communication with the culture directly. Future research may include conducting a survey of the actual "digital natives" to determine if their own perceptions of research, technology and culture are similar or different from the librarian's. In addition, this paper sees the need for additional studies on the perceptions' of library science employees about the needs of higher education students. The research suggests comparing and contrasting the findings with other higher education library staff to determine if the data is common factors are singular in finding or universal about the culture today.

\section{REFERENCES}

1. Bauerlein, M. (2009). The Dumbest Generation: How the Digital Age Stupefies Young Americans and Jeopardizes Our Future (Or, Don't Trust Anyone Under 30). New York, NY: Tarcher.

2. Bauerlein, M. (2011). The Digital Divide. New York, NY: Jeremy P. Tarcher.

3. Bell, M. A. (2011). Native knowledge: Knowing what they know- and learning how to teach them the rest. In H. Gautschi, \& M. Manafy (Eds.). Dancing with Digital Natives: Staying in Step with the Generation That's Transforming the Way Business Is Done. (pp. 351-372). Chicago: Information Today, Inc.

4. Brindley, D. J. (2009). Challenges for Great Libraries in the Age of the Digital Native. Information Services and Use. Volume 29. Issue 1. pp. 3-12.

5. Brown, J.S. \& Duguid, P. (2000). The Social Life of Information. Boston: Harvard Business School Press. 
6. Carr, N. (2011). The Shallows: What the internet is Doing to Our Brains (Reprint). W. W. Norton \& Company.

7. Christensen, C., Johnson, C.W., \& Horn, M.B. (2010). Disrupting Class, Expanded Edition: How Disruptive Innovation Will Change the Way the World Learns. $\left(2^{\text {nd }}\right.$ ed.). McGraw-Hill.

8. Cassidy, E., Britsch, J., Griffin, G., Manolovitz, T., Shen, L. \& Turney, L. (2011). Higher Education and Emerging Technologies: Student Usage, Preferences, and Lessons for Library Services. Reference \& User Services Quarterly, 50(4), 380-391.

9. Erisman, A. M. (2011). Ethics, technology, and the Net Generation: Rethinking IP law. In H. Gautschi, \& M. Manafy (Eds.). Dancing with Digital Natives: Staying in Step with the Generation That's Transforming the Way Business Is Done. (pp. 211-248). Chicago: Information Today, Inc.

10. Evans, B. (2011). When Facebook Comes to Work: Understanding the Work Practices of the Digital Native. In H. Gautschi, \& M. Manafy (Eds.). Dancing with Digital Natives: Staying in Step with the Generation That's Transforming the Way Business Is Done. (pp. 3-18). Chicago: Information Today, Inc.

11. Firat, M. (2013). Multitasking or Continuous Partial Attention: A Critical Bottleneck for Digital Natives. Turkish Online Journal of Distance Education, 14(1), 266-272.

12. Hull, R. (2011). The Digital Natives are the entertainment! In H. Gautschi, \& M. Manafy (Eds.). Dancing with Digital Natives : Staying in Step with the Generation That's Transforming the Way Business Is Done. (pp. 191210). Chicago: Information Today, Inc.

13. Kim, K. \& Sin, Sei-Ching J. (2011). Selecting quality sources: Bridging the gap between the perception and use of information sources. 2011 37: 178-188. Originally published online 28 February 2011 Journal of Information Science. Sage Publications.

14. Marshall, P., Hermana, S., \& Rajana, S. (2006). In search of more meaningful search. Serials Review, 32, 172 180.

15. Prensky, M. (2001). Digital Natives, Digital Immigrants. On the Horizon (MCB University Press), 9(5), 1-6.

16. Randeree, E., \& Mon, L. (2011). Searching for Answers in a Google World. The Reference Librarian, 52 (4), 342-351. DOI: 10.1080/02763877.2011.584504.

17. Sharkey, J. and O'Connor, L. (2013). Establishing Twenty - first Century Information Literacy Fluency. Reference \& User Services Quarterly. Fall 2013, 53(1). 33-39.

18. Tapscott, D. (1998). Growing up digital: the rise of the Net generation. New York; London: McGraw-Hill.

19. Turkle, S. (2011). Alone Together: Why We Expect More from Technology and Less from Each Other (1st ed.). Basic Books.

20. Underberg, N.M., \& Zorn, E. (2013). Digital Ethnography: Anthropology, Narrative, and New Media. Austin: University of Texas Press.

21. Zeitlyn, D., \& Houtman, G. (1996, June). Information Technology and Anthropology. Royal Anthropological Institute. Retreived, March 1, 2014, from, http://lucy.ukc.uk/rai/AnthToday/Zhout.html. 